\title{
Language Attitudes and Communication in the Public Space: A Rural Case Study in South Africa $^{1}$
}

\section{Chrismi-Rinda Loth}

\section{Abstract}

The constructionist perspective considers attitudes to be interactionally emergent and contextually-situated communicative events, instead of preexisting stable entities. As such, there is usually some degree of discrepancy between professed attitudes and actual behaviour. This article explores the linguistic reactions to three different types of communicative events, namely evaluative reactions (elicited language attitudes), spoken communication, and language choices made on public signage (i.e. the linguistic landscape) in the Kopanong Local Municipality in the southern Free State province. At first there appears to be significant deviation between the linguistic reactions in the three contexts. However, upon closer inspection these 'deviations' are in fact congruent with the local linguistic culture, thereby revealing the social consensus underlying linguistic interaction in this area. This revelation confirms the importance of studying social phenomena in context and proves the value of comparative studies in sociolinguistic research.

Keywords: Linguistic landscape, language attitudes, linguistic culture, constructionism, Kopanong Local Municipality

${ }^{1}$ I'd like to express my gratitude to Jani de Lange (Department of South African Sign Language and Deaf Studies, UFS) for her assistance in collecting the data. 


\section{Introduction}

This case study explores the correlation between the language attitudes and behaviours expressed in three different communicative contexts in the Kopanong Local Municipality (southern Free State province, South Africa). These three contexts comprise the attitudes elicited during ethnographic research (evaluative reactions), observations of spoken interaction during the same ethnographic study, and the linguistic choices displayed on public signs (the linguistic landscape).

All three instances of interaction constitute a different type of communicative event. When exploring the link between language attitudes and behaviour, it is vital to keep the 'principle of compatibility' in mind (Soukup 2012: 218f). This principle dictates that attitudes and related behaviours should be elicited in similar contexts in order to explore any correlation. The shared context in all three cases is that they relate to communication in the public space.

The evaluative reactions are those perceptions regarding languages in the speech community that interviewees expressed as being representative of their local linguistic culture. The observations and analyses of public spoken interaction reveals the consensus regarding the linguistic codes suitable for interaction in public. The code choices on public signs erected by private bodies (home owners, economic enterprises, social groups, graffiti artists) constitute the linguistic landscape corpus. There are only vague official guidelines regarding linguistic choices on public signage and the results are thus the choices deemed appropriate for the public space by the local community. Together, these three communicative contexts reveal the prevalent norms regarding language choice during public communication in the research site.

\section{Language Attitudes}

Attitude research originated in social psychology. The classic definition by Eagly and Chaiken (1993: 1) states: 'Attitude is a psychological tendency that is expressed by evaluating a particular entity with some degree of favor or disfavor.' However, attitudes are not only psychological, but also inherently social. They are the result of interaction between individuals and society, which includes processes of socialisation as well as exposures to information (Albarracín, Zanna, Johnson \& Kumkale 2005: 6). There is sometimes a high degree of social consensus on certain attitudes, to the extent that some might construe it as social reality (Albarracín et al. 2005: 4-5). Similarly, language 


\section{Chrismi-Rinda Loth}

attitudes are embedded in social and cultural contexts (Albarracín et al. 2005: 15; Bangeni \& Kapp 2007: 255; Choi 2010: 82; Eagly \& Chaiken 1993). This includes the linguistic culture (Schiffman 1996; 2006). 'Linguistic culture' refers to those prevalent beliefs and conventions regarding the functions and values of languages within speech communities.

Language attitudes are understood as the judgments about the status, value and importance of a language (Baker 1992: 10). Classic language attitude research has viewed attitudes as stable entities, which meant that uncovering these would predict behaviour. However, researchers discovered that there is often a large degree of incongruence between attitude and actual behaviour (Baker 1992; Fishman 1966). This incongruence is the outcome of human adaptability - different contexts elicit different behavioural choices (Baker 1992: 15f). As stated by Ajzen (1988: 45), '(e)very particular instance of human action is, in this way, determined by a unique set of factors. Any change in circumstances, be it ever so slight, might produce a different reaction.' This statement is at the core of the constructionist perspective on attitudes. Instead of viewing these as pre-existing and stable entities, attitudes are expressed as interactionally emergent and contextually-situated communicative events (Soukup 2012). This latter definition is how the present article considers language attitudes.

\subsection{Integration and Instrumentality}

Gardner and Lambert (1959) identify two motivations behind language acquisition, namely instrumental and integrative. Similarly, Ryan and Giles (1982) categorise the motivations behind the actions of speech communities as status and solidarity. Instrumental motivations are mostly pragmatic in nature. Speakers may learn or use a language because it affords them social recognition or economic advantages (status). Integrative motivations refer to the social and interpersonal reasons inspiring the acquisition or use of a language. Speakers may express attachment to or identification with a specific group by using a language associated with said group (solidarity).

However, this division is neither clear-cut nor mutually exclusive (Baker 1992: 124). In critique of this division, Ager (2001: 124) states that: 'There is a desire on the part of the individual or community to assess how far their own behaviours is appropriate to the circumstances they find themselves in, and what consequential action they should take.' This statement appears to 
reflect the notion that, regardless of the motivation behind the choice, speakers (or institutions) make the language choices that they deem most suited to the prevalent linguistic culture.

This study will now proceed to explore the linguistic culture of the Kopanong Local Municipality in the Free State province. It will include a summary of the elicited language attitudes and observed spoken communication. An analysis of code choices on public signs (i.e. the linguistic landscape) adds a third dimension to the study.

\section{The Linguistic Culture of the Kopanong Local Municipality}

The southern Free State province is divided into five district municipalities, including the Xhariep District Municipality. The latter is divided into four local municipalities, namely Kopanong, Letsemeng, Mohokare and Naledi. The rsearch site, Kopanong Local Municipality (KLM), is comprised of nine towns, namely Trompsburg, Philippolis, Springfontein, Reddersburg, Edenburg, Fauresmith, Jagersfontein, Gariep Dam and Bethulie (see Figure 1 below).

\section{Figure 1: The Kopanong Local Municipality}

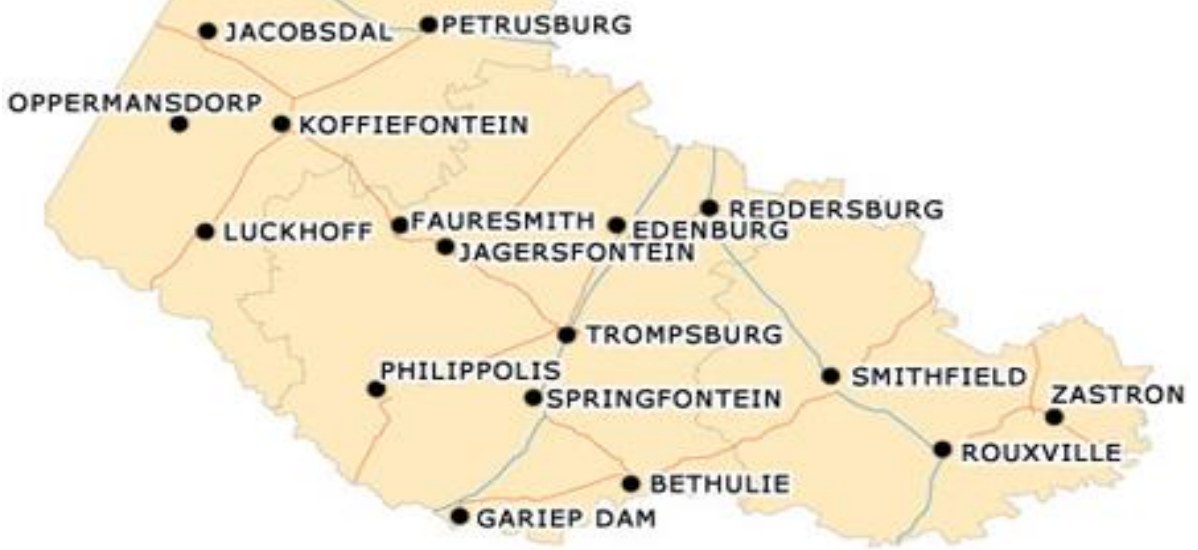

Source: http://www.kopanong.gov.za/index.php/towns-mainmenu-35

(Accessed 12 September 2017.) 
The KLM hosts a culturally diverse population, which is accompanied by a high degree of societal multilingualism.

\subsection{Multilingualism in Kopanong}

Respondents to the 2011 Census (SSA 2011) were asked to indicate which two languages they speak most often: 'Which two languages does (name) speak most often in this household?' '(name)' refers to all the individuals in the household)' (Census 2011 questionnaire downloaded from https://www.statssa.gov.za/census2011/CensusQuestionnaire.asp (Accessed on 19 September 2014). The range of responses indicates the variety of languages spoken in the area (see Figure 2 below).

Figure 2: Distribution of the most frequently spoken languages in the Kopanong Local Municipality

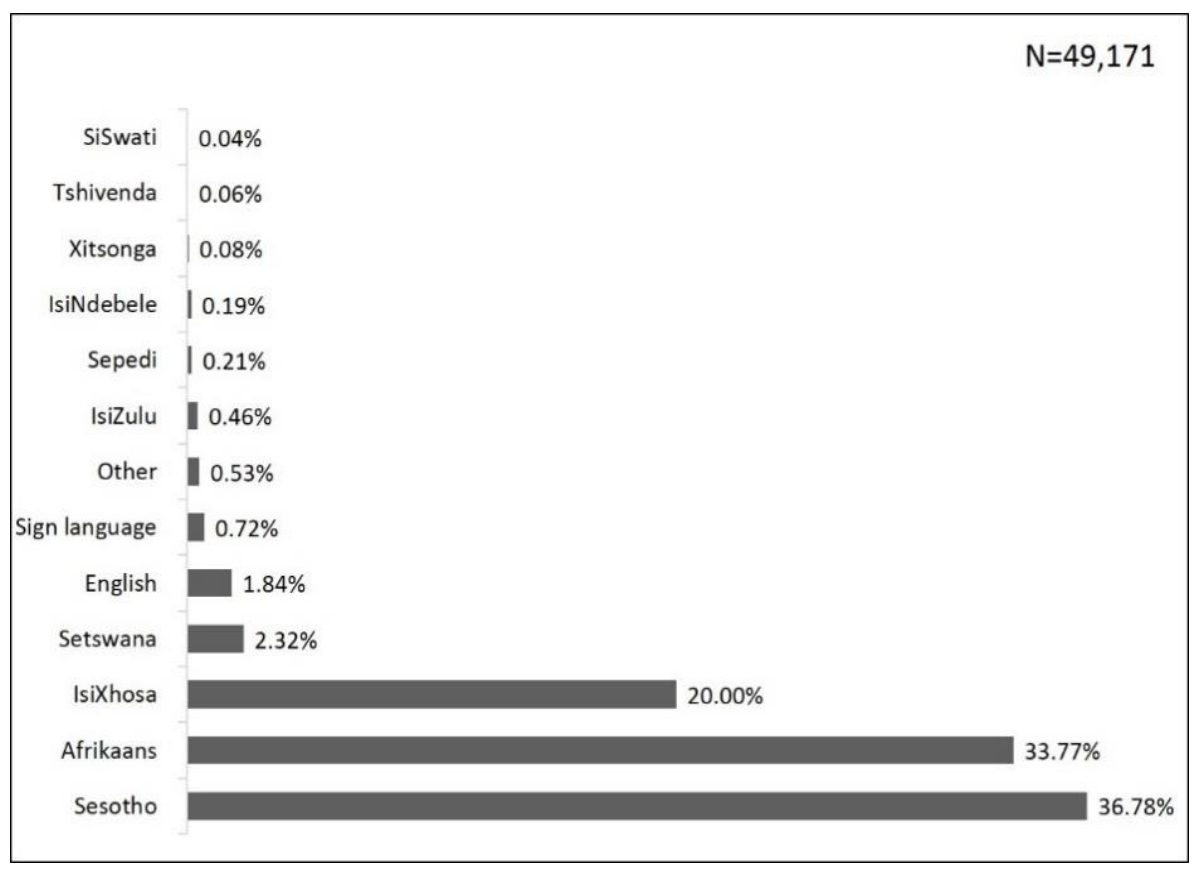

(Source: SSA 2011) 
An indigenous African language is the most frequently spoken language of $60.13 \%$ of the KLM population. The most prominent is Sotho (36.78\%), followed by Xhosa (20\%). Afrikaans is spoken almost as frequently as Sotho (33.77\%). Noticeably, English is the dominant spoken language for only $1.84 \%$ of the community. A number of other languages are also used, but with the exception of Tswana (2.32\%), less than $1 \%$ of the community indicated these as the languages they speak most often. This societal multilingualism is supported on policy level. The KLM's draft language policy is in the form of a by-law (KLM s.a.) which designates Afrikaans, Sotho, Tswana, Xhosa and English as the official municipal languages.

Earlier research (Yperzeele 2009; Cuvelier, Meeuwis, Vandekerckhove \& Yperzeele 2010; Du Plessis 2010) has revealed that multilingual competencies tend to be concentrated along ethnic groupings (as categorised by the Census). There are very few English first-language speakers in the community. 'Whites' thus mainly refers to white people who are native speakers of Afrikaans. This group is at most bilingual (with English as their additional language) and very few have learned the local African languages. The Coloured group also comprises native Afrikaans speakers who have added English competency. Some members of the older generation can speak Sotho as a result of former living arrangements, where the Coloured and African groups shared a neighbourhood before segregation. The African group is the most multilingual, with most individuals speaking two or more African languages (usually the two dominant local languages, Sotho and Xhosa), Afrikaans, and English, the latter with varying levels of fluency. Sotho is the link language amongst the Black African population group. Previous research reveals that language attitudes are also divided along ethnic lines.

\subsection{Language Attitudes in Kopanong}

Yperzeele (2009) provides an in-depth analysis of the role of language attitudes in the delivery of public services. The methodology included in-depth interviews, participant observations and policy analyses. Her analysis included the language attitudes of both civil servants and members of the public. This study was followed by Cuvelier et al.'s (2010) deeper analysis of the prevalent language attitudes, including the locally dominant views on multilingualism per se. The data was further analysed by Du Plessis (2010) in terms of bottomup language planning; a study that further served to elucidate the linguistic 


\section{Chrismi-Rinda Loth}

culture prevalent in the area. Together, these three studies provide insight into the prevalent language attitudes in the community.

\section{AFRIKAANS}

The main instrumental value of Afrikaans lies in it being the interethnic lingua franca. It remains, for the most part, the language of local commerce. Knowledge of this language thus facilitates economic participation. The native speakers of the languages (the white and Coloured population) value the language as a signifier of identity. The Black African population does not value the language per se, but rather as an addition to their prestigious multilingual repertoire.

\section{AFRICAN LANGUAGES}

African languages have very low instrumental value amongst all language groups. The white and Coloured sections of the community appear to be indifferent to these languages. African languages do not prove a threat to Afrikaans and there is no perceived necessity to learn them. Even the native speakers of the African languages acknowledge their limited domain function, but they attach a high integrative value to these languages for their ability to signify a Pan-African identity.

\section{ENGLISH}

English is used mostly only in formal situations (except, of course, when speakers blend languages), and general proficiency in this language is quite low. As such, it does not serve an integrative purpose. However, it does have two instrumental functions. First, it is the language used to accommodate tourists. Second, it is viewed as the language of social mobilisation, especially by the Black African population. The White Afrikaans population, on the other hand, often expresses a neutral or even negative evaluation of English, especially as far as it is perceived to pose a threat to the status of Afrikaans.

\section{MULTILINGUALISM}

Multilingualism is highly valued by the whole community. Mono- or bilingual speakers appreciate the fact that the multilingualism of others allows them to 
continue operating in their own languages. However, this means that linguistic accommodation is often one-sided. In addition to the practical value of being multilingual, multilingual speakers enjoy the measure of social prestige attached to their extensive repertoires. This multilingualism is also perceived to form part of the Pan-African identity.

These localised language attitudes are aligned with national linguistic sentiments. According to Orman (2008: 94), 'a clear language hierarchy has emerged with English at the top, the Bantu languages at the bottom and Afrikaans somewhere in the middle but gradually sinking'. English is considered a language of prestige both because of its international status as well as its (perceived) function as a tool for upward social mobility (Kamwangamalu 2001: 81, 84). Indigenous African languages have a low economic value and status in the public space (Kamwangamalu 2001: 82). However, Mesthrie (2006: 156, 160-161; 2008: 329) points out that indigenous African languages have a covert value. Since they carry a local rather than an international load; and since not one single indigenous African language functions as a lingua franca among the Black African population group, they use their multiple competencies to negotiate identities in a variety of contexts. Afrikaans, conversely, has attained a negative connotation amongst some groups, given its association with the previous regime, but it remains a viable language especially in the private domain (Kamwangamalu 2001: 81). The extensive multilingualism amongst South Africans is reflected in the Constitution (RSA 1996), which accords official status to eleven languages in the country.

Given that attitudes are not a precise indication of behaviour, spoken interaction in the KLM is observed as a separate communicative context.

\subsection{Spoken Communication in Kopanong}

Yperzeele (2009) observes that variations of the phrase 'language is not an issue here' are frequently repeated. For the most part this is because the high level of societal multilingualism facilitates effective communication in two ways; accommodation and facilitation. First, multilingual speakers accommodate less multilingual speakers by switching to a language the latter party understands or by converging to the lingua franca (Afrikaans). In most cases, the accommodation would be on the side of the African language speakers. There are also instances of divergence, where each party speaks their 


\section{Chrismi-Rinda Loth}

own language while still understanding the other. This is a common occurrence amongst speakers of African languages, but also between native speakers of Afrikaans and English. While some degree of negotiation to find an appropriate code is required, willingness to accommodate is assumed since it is such a prominent aspect of the local linguistic culture. Second, a limited form of language facilitation takes place by means of informal interpreting and translation, where multilingual but untrained members of the community step in. Effective communication in this area is thus dependent on the willingness of the multilingual parties to accommodate, even though this accommodation remains mostly one-sided.

\subsection{The Linguistic Landscape}

The definition of the 'linguistic landscape' has expanded from the broad description 'the use of language in its written form in the public sphere' (Gorter 2006: 2) to include other factors contributing to the semiotic aspects of the LL, such as clothing, images, sounds, movements, buildings and other multimodal aspects. This multimodal focus is evident in the definition provided by the editors of the new journal Linguistic Landscape: '... the presence, representation, meanings and interpretation of languages displayed in public places...' (Shohamy \& Ben-Rafael 2015: 1). However, this study is concerned with a specific aspect of the LL, namely public signs. The latter is defined by Backhaus (2005: 17-18) as 'an inscribed surface displayed in public space in order to convey a message to a non-specified group of readers'.

Communication on signs is inherently different from spoken interaction (Backhaus 2005: 21-22). First, the message is indexical - a sign must be viewed in an appropriate physical location in order for its meaning to be understood, i.e. a stop sign attached to a building would be meaningless. In this way, it is also different from other forms of written communication that are not dependent on emplacement, such as letters, books and newsletters. Second, the communication is static. The readership is undefined, the sign writer is usually unknown, and as such there can be no negotiation regarding the most appropriate linguistic code, as is done during spoken interaction.

Language attitudes also influence code choices on signs. Shohamy (2006: 110) views the linguistic landscape as a covert language policy mechanism, whereby the presence or absence of languages sends specific messages regarding attitudes towards certain languages or language groups. 
Languages displayed in the LL contribute to a positive social identity of the group whose language is used, thereby contributing to the ethnolinguistic vitality of said group, as concluded by Landry and Bourhis (1997). However, by including certain groups, others are excluded and thus marginalised. In other words, language ideologies and attitudes are turned into practice (i.e. code choices) and these 'represent different views on the linguistic arrangement of a place' (Backhaus 2005: 32; see also Ben-Rafael, Shohamy, Amara \& Trumper-Hecht 2006: 27). In other words, the linguistic landscape is another window onto the linguistic culture of a community.

\section{Methodology}

The data from the linguistic landscape was collected and analysed in accordance with a combined quantitative/qualitative approach. As argued by Blackwood (2015: 38-53), this allows for cross-referencing - quantitative data contextualises language use, while a qualitative analysis prevents impressionistic conclusions. The extensive empirical dataset was collected between 20 May 2008 and 18 August 2010 by two researchers (post-graduate students). They photographed every public sign with linguistic text visible from street level in all the nine towns of the KLM. Public signs are defined as 'any piece of written text within a spatially definable frame' (Backhaus 2005: 96) that are stationary (in other words, erected or affixed signs, excluding other semiotic modes such as slogans on t-shirts). Each sign was recorded as a single database entry.

\section{CATEGORISATION}

The categorisation considers three variables, namely agency, locality and functionality. Agency refers to those responsible for making language choices on signage. The prevailing working (although contested) definition of agency is based on the dichotomy between top-down agents (government institutions) and bottom-up agents (private actors). This distinction remains relevant, because contributions from these two domains are different, as proven by various former studies (cf. inter alia, Backhaus 2005; Ben-Rafael et al. 2006; Du Plessis 2007; Shohamy 2006). In other words, these two types of agents have 'two different ways of marking the territory' (Calvet, quoted in Backhaus 2005: 41). Du Plessis (2011: 194, 220-221) proves that local and external role- 


\section{Chrismi-Rinda Loth}

players also make different linguistic choices. Since the present study explores the linguistic culture of the local community, only locally-produced bottom-up signs are considered.

Locality refers to where signs are found. Previous LL research has proven that there is indeed a correlation between neighbourhoods and their LLs (cf. Ben-Rafael et al. 2006; Ben-Rafael \& Ben-Rafael 2015; Shohamy 2015: 165-166). However, it is important to note that the correlation between the LL and a locality does not imply a similar correspondence between the LL and the ethnolinguistic composition of the community settled in the neighbourhood. Instead, the LL is a reflection of the linguistic resources available to the inhabitants (Ben-Rafael et al. 2006: 14; Extra \& Barni 2008: 3). In the present study the demographic profile of the research site reveals that ethnolinguistic groups settled in geographically confined concentrations in the KLM. The geographical boundaries are defined in terms of locales, or different types of neighbourhoods, which are separated by physical distance. These neighbourhoods can be divided into three suburb types, namely Coloured Areas, Former White Towns and Townships. These settlements are a remnant from the previous apartheid policy, where neighbourhoods were divided among ethnic lines. Although the boundaries are starting to blur, the distinction remains clear enough to even a casual observer.

Functionality relates to the purpose a sign is intended to serve (cf. Du Plessis 2011). Therefore, the code choice on a sign reflects what functions the languages displayed are perceived to be able to perform. The signs erected by local, bottom-up agents in this community serve commercial purposes; identify or provide information about initiatives; decorate or declare ownership of homes; or constitute graffiti.

\section{ANALYSIS}

The analysis explores the language choices displayed on signs. In this LL, the languages used are indigenous African languages (Sotho, Tswana, Xhosa and Zulu), Afrikaans, English, as well as various combinations of these languages. The African languages had such a low degree of visibility that they had to be grouped together as one linguistic code in order to have statistical relevance. The analysis considers the prevalence of the three codes (African language, Afrikaans and English), as well as code distribution, i.e. the combinations the various languages are used in. 


\section{Communication in the Linguistic Landscape in Kopanong}

The dataset comprises of 3,724 signs. Given that the Former White Towns are the main centre, this locality contributed the majority of signs $(56.85 \%$ or $\mathrm{N}=2,117)$ to the dataset. About a third of the signs $(32.44 \%, \mathrm{~N}=1,208)$ are located in the Townships, where the majority of the population lives. In line with the size of its population, only $10.71 \%(\mathrm{~N}=399)$ of signs are displayed in the Coloured Areas. This section first explores how codes are utilised in each of the localities. It then investigates how often the three codes (Afrikaans, English and African languages) are used in each of the three localities. Since multilingualism is such a salient feature of the community, its prevalence in each of the three localities is also explored.

\subsection{Code Distribution per Locality and Function}

In all three localities, commercial signs and those on homes make up the most of the LL. Commercial signs include advertisements and business names of economic enterprises such as shops, guest houses, goods for sale and services provided. Signs directed at tourists are most likely to be found in the Former White Towns, since these are the main centres of each town. The signs on homes serve to decorate the residence, to indicate affiliation, usually with a soccer team or political party, or declare ownership, such as a 'welcome' sign or a warning regarding the presence of dogs or alarm systems. Initiatives, such as community organisations or social groups, use signs to identify their location or to invite public participation in their activities. The graffiti is usually no more than indecipherable scribbles and random phrases.

\section{FORMER WHITE TOWNS}

In the Former White Towns, the most prevalent choice is monolingual English for commercial purposes $(30.09 \%)$. Another significant trend is the use of either the bilingual Afrikaans/English code (14.17\%) or monolingual Afrikaans (13.89\%) on commercial signs. Noticeably, the former code is also used on private homes $(6.14 \%)$, although monolingual Afrikaans and the multilingual African language/Afrikaans/English code is used more often (both $8.36 \%$ ). The latter code is used most often on warning signs.

Figure 3 below displays the code distribution in the Former White Towns. 
Figure 3: Code distribution in the linguistic landscapes of Former White Towns in Kopanong

\begin{tabular}{|c|c|c|c|c|}
\hline \multirow[b]{2}{*}{ Code } & \multicolumn{4}{|c|}{ Sign function } \\
\hline & Commercial & Initiative & Home owner & Graffiti artist \\
\hline Uncertain & & & $0.28 \%$ & $0.24 \%$ \\
\hline African language only & $0.19 \%$ & & $0.14 \%$ & $0.05 \%$ \\
\hline Afrikaans only & $13.89 \%$ & $3.92 \%$ & $8.36 \%$ & $0.14 \%$ \\
\hline English only & $30.09 \%$ & $2.17 \%$ & $3.83 \%$ & $0.43 \%$ \\
\hline $\begin{array}{l}\text { Bilingual African } \\
\text { language/Afrikaans }\end{array}$ & $0.14 \%$ & $0.05 \%$ & $0.24 \%$ & \\
\hline Bilingual African language/English & $2.22 \%$ & $0.05 \%$ & $0.99 \%$ & $0.38 \%$ \\
\hline Bilingual Afrikaans/English & $14.17 \%$ & $1.89 \%$ & $6.14 \%$ & $0.24 \%$ \\
\hline $\begin{array}{l}\text { Multilingual African } \\
\text { language/Afrikaans/English }\end{array}$ & $1.32 \%$ & $0.05 \%$ & $8.36 \%$ & $0.05 \%$ \\
\hline
\end{tabular}

\section{COLOURED AREAS}

Again, the code used most often is English-only for commercial purposes (19.05\%). In sharp contrast to the Former White Towns, however, residents in Coloured Areas also display this code prominently on their homes (17.04\%). The monolingual Afrikaans code is also used prominently for this purpose $(13.03 \%)$, although it is used far less frequently for commercial purposes (5.51\%). Instead, the bilingual Afrikaans/English code appears to be the more favoured choice (12.03\%). Again, the multilingual African languages/ Afrikaans/ English code is mostly used for warnings on homes.

The code distribution in Coloured Areas is shown in Figure 4 below: 


\section{Figure 4: Code distribution in the linguistic landscapes of Coloured Areas in Kopanong}

\begin{tabular}{|c|c|c|c|c|}
\hline \multirow[b]{2}{*}{ Code } & \multicolumn{4}{|c|}{ Sign function } \\
\hline & Commercial & \begin{tabular}{|l|l} 
Initiative & \\
\end{tabular} & Home owner & Graffiti artist \\
\hline Uncertain & $0.25 \%$ & & $0.75 \%$ & $4.76 \%$ \\
\hline African language only & $0.25 \%$ & & $1.25 \%$ & $0.75 \%$ \\
\hline Afrikaans only & $5.51 \%$ & $0.75 \%$ & $13.03 \%$ & $0.75 \%$ \\
\hline English only & $19.05 \%$ & $1.25 \%$ & $17.04 \%$ & $3.76 \%$ \\
\hline $\begin{array}{l}\text { Bilingual African } \\
\text { language/English }\end{array}$ & $1.75 \%$ & & $2.51 \%$ & $2.26 \%$ \\
\hline Bilingual Afrikaans/English & $12.03 \%$ & $1.50 \%$ & $4.26 \%$ & \\
\hline $\begin{array}{l}\text { Multilingual African } \\
\text { language/Afrikaans/English }\end{array}$ & $0.25 \%$ & & $6.02 \%$ & $0.25 \%$ \\
\hline
\end{tabular}

\section{TOWNSHIPS}

English is the dominant code in the LLs of Townships as well. Whereas the monolingual English code is favoured in the other two localities for commercial purposes, here its use on business signs (17.96\%) is surpassed by its use on private homes $(22.60 \%)$. Two noticeable deviations from the other two localities is the lower preference for Afrikaans and the increased visibility of African languages. The presence of the bilingual Afrikaans/English code is negligible in comparison to its use in Former White Towns and Coloured Areas. Instead, English is used together with an African language (10.10\% for commercial purposes and $7.04 \%$ on homes). This is often achieved by combining an African word with a general English term to create a name, such 
as 'Rethabile Bottle Store'. This is also the only locality where the monolingual African language code is noticeable, especially on homes $(6.87 \%)$.

Figure 5 below illustrates the code distribution in Townships:

Figure 5: Code distribution in the linguistic landscapes of Townships in Kopanong

\begin{tabular}{|c|c|c|c|c|}
\hline \multirow[b]{2}{*}{ Code } & \multicolumn{4}{|c|}{ Sign function } \\
\hline & Commercial & Initiative & Home owner & Graffiti artist \\
\hline Uncertain & & & $4.06 \%$ & $3.48 \%$ \\
\hline African language only & $1.41 \%$ & $0.17 \%$ & $6.87 \%$ & $2.15 \%$ \\
\hline Afrikaans only & $0.75 \%$ & $0.17 \%$ & $5.79 \%$ & $0.08 \%$ \\
\hline English only & $17.96 \%$ & $2.40 \%$ & $22.60 \%$ & $1.82 \%$ \\
\hline $\begin{array}{l}\text { Bilingual African } \\
\text { language/Afrikaans }\end{array}$ & $0.08 \%$ & $0.08 \%$ & $0.50 \%$ & \\
\hline Bilingual African language/English & $10.10 \%$ & $0.41 \%$ & $7.04 \%$ & $4.72 \%$ \\
\hline Bilingual Afrikaans/English & $0.83 \%$ & $1.32 \%$ & $2.32 \%$ & $0.17 \%$ \\
\hline $\begin{array}{l}\text { Multilingual African } \\
\text { language/Afrikaans/English }\end{array}$ & $0.17 \%$ & & $2.48 \%$ & $0.08 \%$ \\
\hline
\end{tabular}

\subsection{Code Prevalence per Locality}

English is by far the most frequently used code in all three localities. It is used on $72.74 \%$ of all locally-produced bottom-up signs in Former White Towns; on $76.33 \%$ of signs in Coloured Areas; and on an even larger portion of signs in Townships (80.48\%). Afrikaans remains prominent in both Former White Towns and Coloured Areas (59.26\% and $47.07 \%$ respectively), but is used on 
less than a fifth of all signs in Townships (16.03\%). The reverse is true for African languages - it is an unpopular choice in the Former White Towns and Coloured areas (14.29\% and $16.22 \%$ respectively), but is used much more often in Townships (38.21\%).

The prevalence of the three codes in each of the localities is displayed in Figure 6 below:

Figure 6: Code prevalence per locality in Kopanong

\section{Total LL: code prevalence/locality}

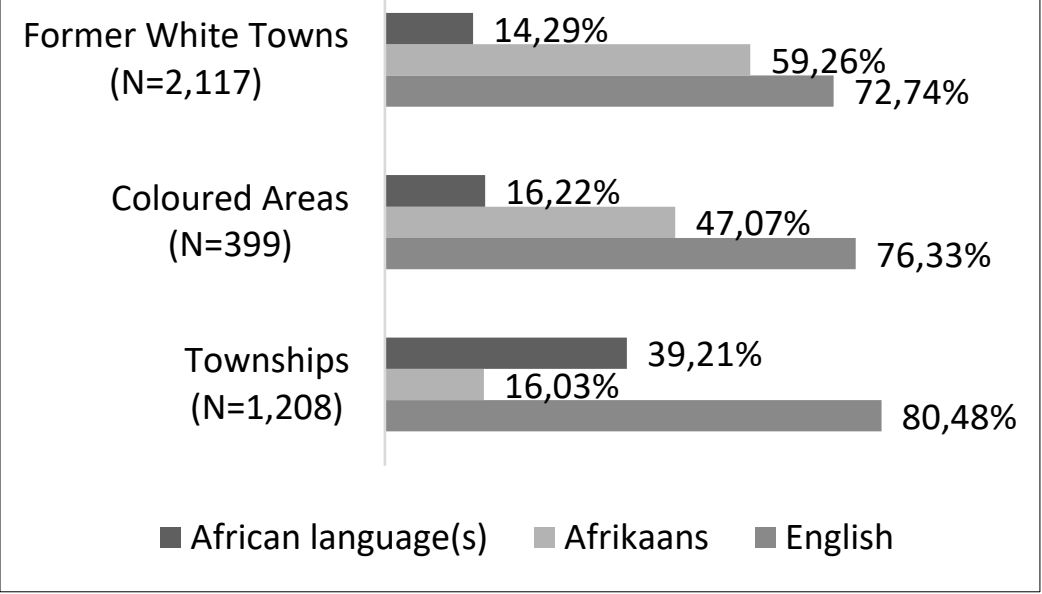

Monolingual code choices are used most frequently by local, bottom-up LL agents in all three localities $-63.25 \%$ of signs in Former White Towns, 63.41\% in Coloured Areas, and $62.17 \%$ in Townships. Signs displaying two codes make up a quarter of code choices in each of the three localities $-26.45 \%$ in Former White Towns, $24.31 \%$ in Coloured Areas and $27.32 \%$ in Townships. Multilingualism is not prominent in the LL of any of the three localities. In Former White Towns, $9.78 \%$ of signs display a multilingual code, in Coloured Areas it is $6.52 \%$ and in Townships a mere $2.98 \%$.

Figure 7 below shows the prevalence of multilingualism in each locality: 


\section{Figure 7: Prevalence of multilingualism in Kopanong}

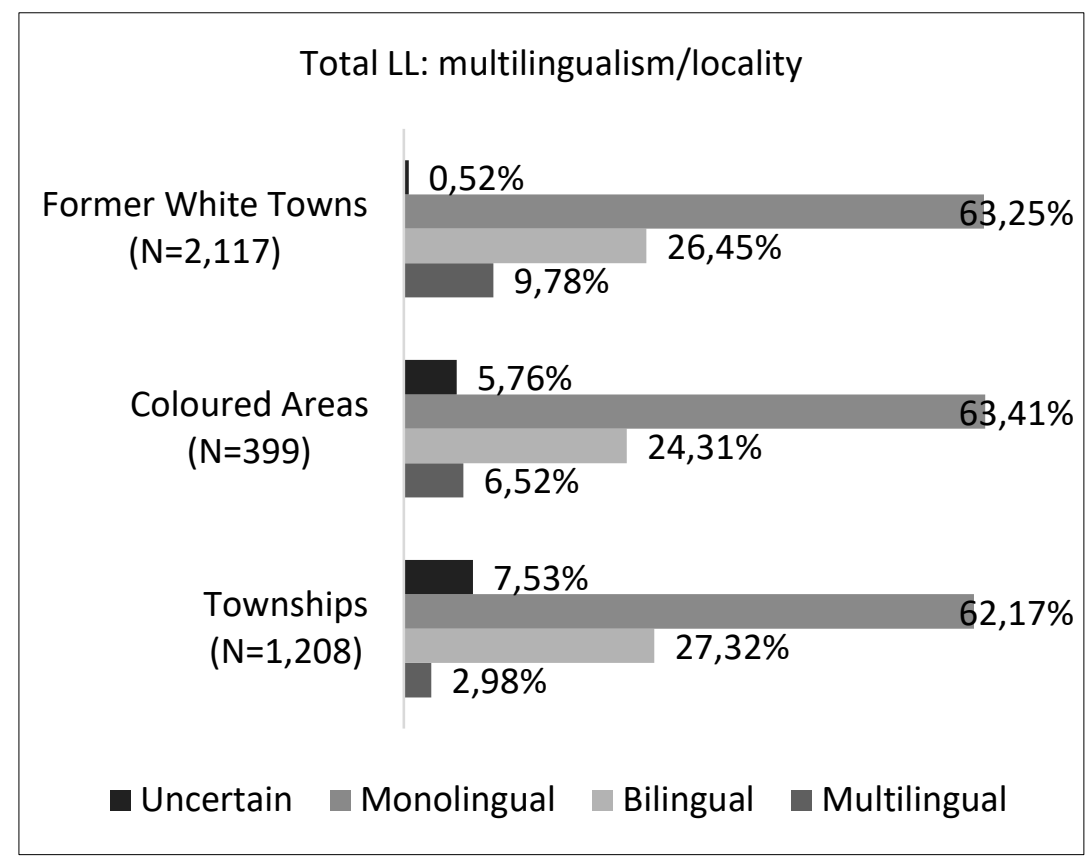

\subsection{Discussion}

At first glance, there appears to be a great discrepancy between the professed language attitudes and patterns of spoken interaction, and the linguistic landscape. The expectation is that Afrikaans will be used prominently in the Former White Towns and the Coloured Areas. African languages should be highly visible in the Townships. A large number of multilingual signs is also anticipated. Given the low proficiency in English, this language is assumed to be an unpopular choice for signage. However, English is overwhelmingly present and the majority of signs are monolingual. A closer discussion of the results is thus required.

Afrikaans is the native language of the majority of inhabitants of the Former White Towns and the Coloured Areas and it still serves as the local language of business. This corresponds to the results from the LL, where this language is used prominently. It is used as a stand-alone code both on homes, 
where it signifies identity, and for commercial purposes. The fact that Afrikaans can be used on its own in the main centres confirms its role as interethnic lingua franca. In the sign in Figure 8 below, the service provided as well as the fees are only displayed in Afrikaans (the service provided is pumping up wheels, at the fees of R 2.00 for one wheel and R 5.00 for four wheels). The inhabitants of the Townships do not attach any particular value to the language. In addition, native speakers of Afrikaans are not expected to visit these locales and therefore they do not have to be accommodated in the linguistic landscape (for example, the sign in Figure 9 below advertises greens for sale only in an African language). There is thus no need for the multilingual inhabitants of Townships to activate this particular segment of their linguistic repertoire. As a result, Afrikaans is far less visible in the Townships.

Figure 8: Monolingual Afrikaans sign in a Former White Town

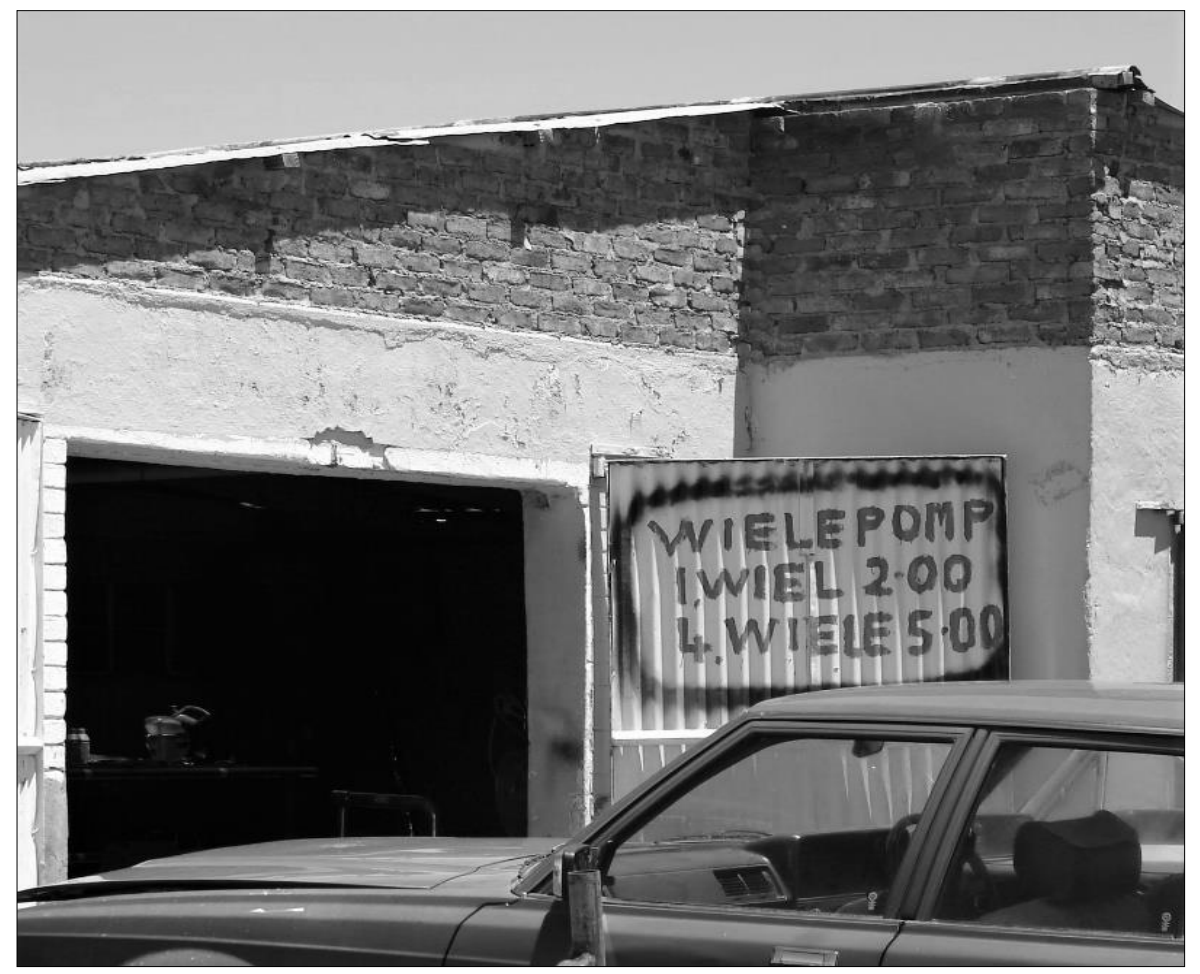


Figure 9: Monolingual African language sign in a Township

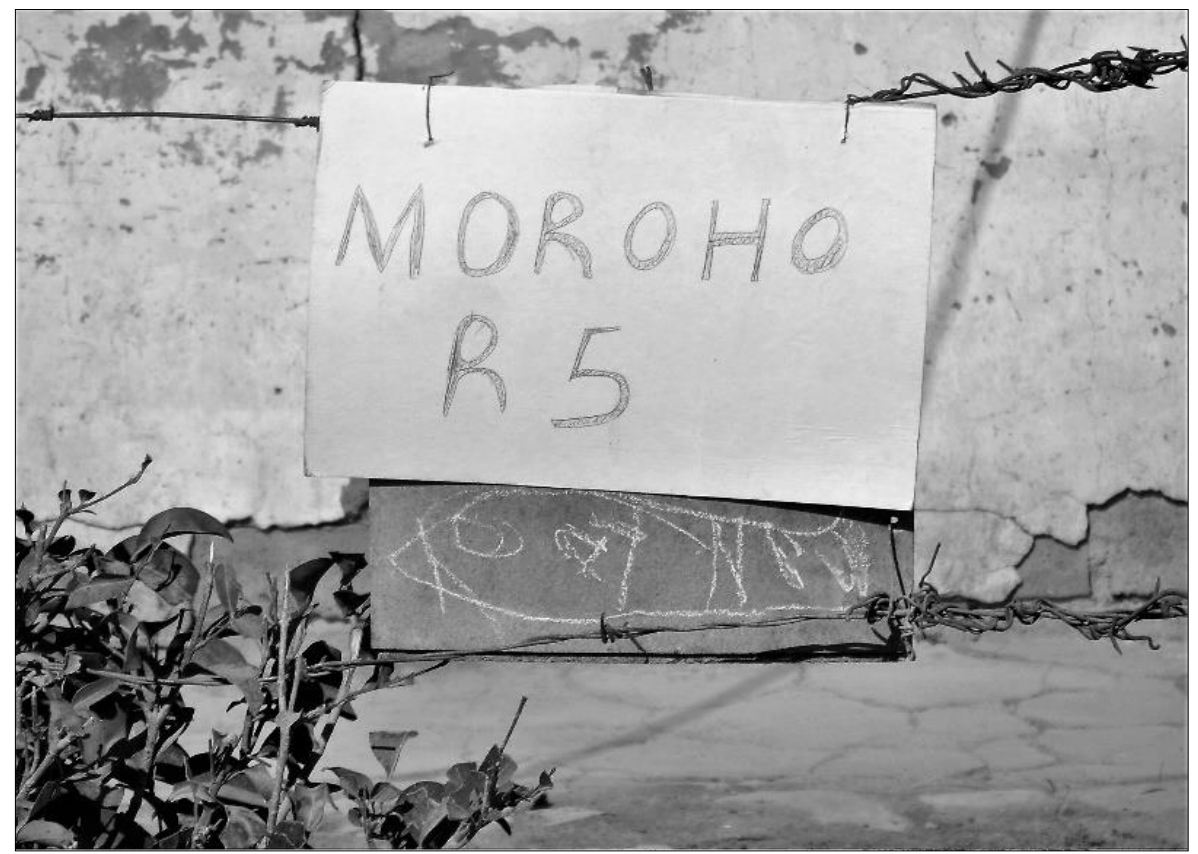

African languages are considered by all linguistic groups to have low instrumental value. Correspondingly, it is the least visible code in the LL in all three localities. In the Former White Towns and Coloured Areas it is used most frequently in conjunction with other languages on pre-manufacture warning signs (see Figure 10 below). As in spoken communication, there is little accommodation in the linguistic landscape to speakers of the African languages. Even in the Townships, where this language group serves an integrative function to the inhabitants, African languages have a low degree of visibility in the linguistic landscape. In addition, as an identity marker it is not often used alone, as Afrikaans is in the Former White Towns and the Coloured Areas. Instead, it is regularly combined with English, a language with no integrative value, as for example in Figure 11 below ('Ngaka ya setso' means 'traditional healer'). The reason might be that the linguistic landscape is viewed as a formal language use domain, for which the African languages are perceived not to be suited. 
Language Attitudes and Communication in the Public Space

Figure 10: Pre-manufactured multilingual warning sign

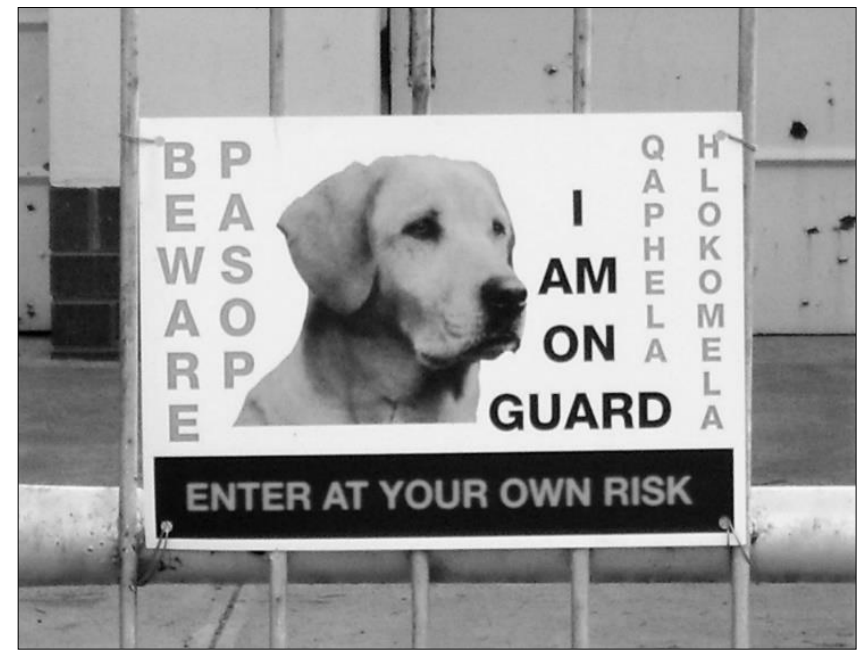

Figure 11: Sign displaying an African language as well as English

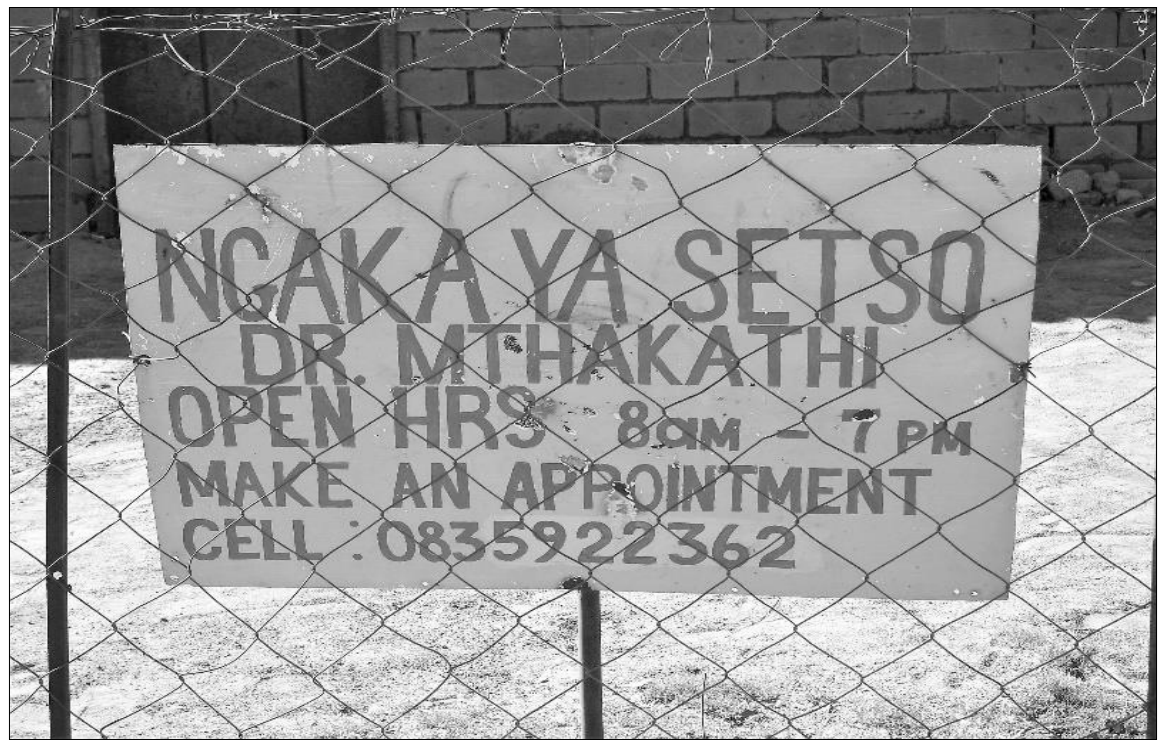




\section{Chrismi-Rinda Loth}

While English is not widely used during spoken interaction, this is certainly not the case for communication via public signs. The perceived economic value of the language is reflected by its use on commercial signs in the Former White Towns, where its instrumental value in accommodating tourists seems to override the negative evaluation some native Afrikaans speakers have of the language. This negative view is confirmed by its absence on homes. In contrast, English is used widely on homes in Coloured Areas and Townships. This confirms the perceived purpose of English as a tool for social mobilisation. English is also often used for commercial purposes in these two locales. Given the lack of verbal proficiency in this language, the assumption is that it's the prestige value of English rather than any instrumental function that motivates this choice. The phenomenon of combining African languages with English in the Townships is a prime example of Mesthrie's (2006; 2008) statement that African languages has covert value and is used to negotiate identity. In this case, solidarity is expressed by using an African language while prestige is added to the home owner or establishment by association with English.

The most surprising outcome relates to the lack of multilingualism in the linguistic landscapes of all three localities. The inhabitants in the Former White Towns and Coloured areas tend to be bilingual at most, and attempts at multilingualism extend to using the bilingual Afrikaans/English code (except for the pre-bought multilingual warning signs, which usually includes at least one African language - not necessarily one used locally). However, speakers from the Township populations are proudly multilingual, but the signs in this locality display the lowest degree of multilingualism. Attempts at multilingualism mostly extend to combining an African language with English. It is difficult to understand this phenomenon without further ethnographic research, though it might be that the high level of multilingualism amongst the target audience negates the necessity of accommodation through multilingual signage.

The greatest apparent discrepancy between the linguistic landscape and the other two communicative relates to the use of English and the level of multilingualism. However, upon closer investigation, a consistent explanation becomes apparent. Code choice remains a context-dependent challenge. During spoken interaction, the linguistic capacity of the interacting parties dictates code choice, especially given the willingness of the multilingual members of the community to accommodate those with a more limited repertoire. When making choices for the linguistic landscape, it is the locality, and therefore the target audience, that determines code choice. Here the 
deciding factor is not linguistic capacity per se, but rather the associations with different code choices shared by the target audience. In the Former White Towns, the apparent integrative value of Afrikaans as a signifier of identity results in a high visibility of this language in the linguistic landscape. The instrumental value of English as a tool of social mobility appears to motivate its choice on public signs in the Townships. Both motivations seem to influence code choices in the Coloured Areas, where Afrikaans and English are accorded high visibility on homes as well as commercial signs.

Accommodation is an important aspect of fluent spoken interaction. This appears to also be the case in the linguistic landscape. The Former White Towns are the main centres of each town. As such, it is frequented by all linguistic groups. The lack of African languages on commercial signs indicates that the speakers of these languages are expected to understand Afrikaans and/or English. Again the accommodation is one-sided, i.e. on the part of the African language speakers. The Coloured Areas are not expected to be visited frequently by the inhabitants of the other two localities. Afrikaans happens to be a shared language with the White population, but African language speakers do not have to be accommodated. Therefore, while Afrikaans is frequently used in the Coloured Areas, African languages are not accorded a noticeable presence. The same reasoning appears to apply in the Townships, where Afrikaans is not required by the target audience.

All in all, the apparent discrepancies appears to be in line with the community's linguistic culture.

\section{Conclusion}

Considering language attitudes from a constructionist approach predicts great discrepancy in terms of language choices within as well as between different communicative contexts. At first glance, this appears to be the case in this paper. However, a closer analysis reveals a systemic pattern. The majority of linguistic choices are executed in accordance to the norms and conventions provided by the local linguistic culture. While every interaction requires some degree of negotiation, the communicative events are well-defined and most speakers appears content to make the choices most suited to the status quo. This consensus is so far-reaching that it appears to have indeed become a social reality (Albarracín et al. 2005: 4-5). As remarked by Yperzeele (2009), the sentiment that 'language is not an issue here' is an established one in this 
community; although the analysis by Du Plessis (2010) reveals that the state of affairs is in fact not so straight-forward. Regardless, the outcomes of this case study shows that language attitudes (both professed as well as enacted) are deeply socially embedded. Since social processes are inherently dynamic, it remains useful to consider linguistic attitudes and behaviours as interactionally emergent and contextually situated rather than as static entities. This study confirms the importance of avoiding the practice of studying social phenomena in isolation. It also proves the value of comparative studies from different sociolinguistic fields.

\section{References}

Ager, D. 2001. Motivation in Language Planning and Language Policy. Clevedon: Multilingual Matters.

Ajzen, I. 1988. Attitudes, Personality, and Behavior. Chicago: Dorsey.

Albarracín, D., M.P. Zanna, B.T. Johnson \& G.T. Kumkale 2005. Attitudes:

Introduction and Scope. In Albarracín, D., B.T. Johnson \& M.P. Zanna (eds.): The Handbook of Attitudes. Mahwah, NJ: Erlbaum.

Backhaus, P. 2005. Signs of Multilingualism in Tokyo: A Linguistic

Landscape Approach. Unpublished doctoral thesis. Duisberg-Essen:

University of Duisberg-Essen.

https://doi.org/10.21832/9781853599170-004

Baker, C. 1992. Attitudes and Language. Clevedon: Multilingual Matters.

Bangeni, B. \& R. Kapp 2007. Shifting Language Attitudes in a Linguistically

Diverse Learning Environment in South Africa. Journal of Multilingual and Multicultural Development 28,4: 253 - 269. Available at: https://open.uct.ac.za/handle/11427/8848 (Accessed on 09 June 2014). https://doi.org/10.2167/jmmd495.0

Ben-Rafael, E. \& M. Ben-Rafael 2015. Linguistic Landscapes in an Era of Multiple Globalizations. Linguistic Landscape 1,1/2: 19 - 37. Available at: http://www.jbe-platform.com/content/journals/10.1075/11.1.1-2.02ben (Accessed on 23 December 2016). https://doi.org/10.1075/11.1.1-2.02ben Ben-Rafael, E., E. Shohamy, M.H. Amara \& N. Trumper-Hecht 2006. Linguistic Landscape as Symbolic Construction of the Public Space: The Case of Israel. In D. Gorter (ed.): Linguistic Landscape: A New Approach to Multilingualism. Clevedon: Multilingual Matters.

https://doi.org/10.21832/9781853599170-002 
Blackwood, R. 2015. LL Explorations and Methodological Challenges: Analysing France's regional languages. Linguistic Landscape 1,1/2: 38 - 53. http://www.jbe-platform.com/content/journals/10.1075/11.1.1-2.03bla (Accessed on 23 December 2016). https://doi.org/10.1075/11.1.1-2.03bla

Choi, J.K. 2003. Language Attitudes and the Future of Bilingualism: The Case of Paraguay. International Journal of Bilingual Education and Bilingualism 6,2: 81 - 94. Available at:

http://www.tandfonline.com/doi/abs/10.1080/13670050308667774

(Accessed on 11 April 2017).

https://doi.org/10.1080/13670050308667774

Cuvelier, P., M. Meeuwis, R. Vandekerckhove \& S. Yperzeele 2010. Multilingualism and Language Attitudes in the Xhariep District: The Case of Kopanong. In Cuvelier, P., T. Du Plessis, M. Meeuwis, R. Vandekerckhove \& V. Webb (eds.): Multilingualism from Below: Studies in Language Policy in South Africa. Pretoria: Van Schaik.

Du Plessis, T. 2007. Een- of Meertalige Openbare Tekens? Perspektiewe op die Regulering van Taalsigbaarheid en die Suid-Afrikaanse Linguistiese Landskap. Tydskrif vir Geesteswetenskappe 47,4: 550 - 567.

Du Plessis, T. 2010. Language Planning from Below: The Case of the Xhariep District of the Free State Province. Current Issues in Language Planning 22,2: 130 - 151. Available at:

http://www.tandfonline.com/doi/abs/10.1080/14664208.2010.505069

(Accessed on 01 January 2011).

https://doi.org/10.1080/14664208.2010.505069

Du Plessis, T. 2011. Language Visibility and Language Removal: A South African Case Study in Linguistic Landscape Change. Communicatio 37,2: 194 - 224. Available at:

http://www.tandfonline.com/doi/abs/10.1080/02500167.2011.604170

(Accessed on 23 October 2012).

https://doi.org/10.1080/02500167.2011.604170

Eagly, A.H. \& S. Chaiken 1993. The Psychology of Attitudes. Orlando, FL: Harcourt Brace Jovanovich.

Extra, G. \& N. Barni 2008. Mapping Linguistic Diversity in Multicultural Contexts: Cross-national and Cross-linguistic Perspectives. In Barni, M. \& G. Extra (eds.): Mapping Linguistic Diversity in Multicultural Contexts. Berlin/New York: Mouton de Gruyter.

https://doi.org/10.1515/9783110207347.1.3 
Fishman, J. 1966. Language Loyalty in the United States. The Hague: Mouton. Gardner, R. \& W. Lambert 1959. Motivational Variables in Second-language Acquisition. Canadian Journal of Psychology 13: 266 - 272. Available at: https://eric.ed.gov/?id=ED031968 (Accessed on 11 April 2017). https://doi.org/10.1037/h0083787

Gorter, D. 2006. Introduction: The Study of the Linguistic Landscape as a New Approach to Multilingualism. In D. Gorter (ed.): Linguistic Landscape: A New Approach to Multilingualism. Clevedon: Multilingual Matters. https://doi.org/10.21832/9781853599170

Kamwangamalu, N.M. 2001. Ethnicity and Language Crossing in PostApartheid South Africa. International Journal of the Sociology of Language 152: 75 - 95. Available at:

https://www.degruyter.com/view/j/ijsl.2001.2001.issue152/ijsl.2001.058/ijs1.2001.058.xml (Accessed on 17 December 2015). https://doi.org/10.1515/ijs1.2001.058

KLM (Kopanong Local Municipality). S.a. Kopanong Local Municipality Language Policy. Unpublished document. Available on request from mm@kopanong.gov.za

Landry, R. \& R.Y. Bourhis 1997. Linguistic Landscape and Ethnolinguistic Vitality: An Empirical Study. Journal of Language and Social Psychology 16,1: 23 - 49. Available at:

http://journals.sagepub.com/doi/abs/10.1177/0261927X970161002

(Accessed on 21 February 2011).

https://doi.org/10.1177/0261927X970161002

Mesthrie, R. 2006. Language, Transformation and Development: A Sociolinguistic Appraisal of Post-Apartheid South African Language Policy and Practice. Southern African Linguistics and Applied Language Studies 24,2: 151 - 163. Available at:

http://www.tandfonline.com/doi/abs/10.2989/16073610609486414 (Accessed on 23 August 2014).

Mesthrie, R. 2008. South Africa: The Rocky Road to Nation Building. In A. Simpson (ed.): Language and National Identity in Africa. Oxford: Oxford University Press.

Orman, J. 2008. Language Policy and Nation-Building in Post-Apartheid South Africa. Berlin: Springer.

RSA (Republic of South Africa) 1996. Constitution of the Republic of South Africa, Act 108 of 1996. Pretoria: Government Printers. 
Ryan, E.B. \& H. Giles 1982. Attitudes towards Language Variation. London: Edward Arnold.

Schiffman, H.F. 1996. Linguistic Culture and Language Policy. London: Routledge.

Schiffman, H.F. 2006. Language Policy and Linguistic Culture. In Ricento, T. (ed.): An Introduction to Language Policy: Theory and Method. Malden, MA: Blackwell.

Shohamy, E. 2006. Language Policy: Hidden Approaches and New Agendas. London/New York: Routledge. https://doi.org/10.4324/9780203387962

Shohamy, E. 2015. LL Research as Expanding Language and Language Policy.

Linguistic Landscape 1,1/2: 152 - 171. Available at:

https://benjamins.com/\#catalog/journals/ll.1.1-2.09sho/details (Accessed on 23 December 2016). https://doi.org/10.1075/11.1.1-2.09sho

Shohamy, E. \& E. Ben-Rafael 2015. Introduction. Linguistic Landscape. A

New Journal. Linguistic Landscape 1,1/2: 1 - 5. Available at:

http://www.jbe-platform.com/content/journals/10.1075/11.1.1-2.001int

(Accessed on 23 December 2016). https://doi.org/10.1075/11.2.3

Soukup, B. 2012. Current Issues in the Social Psychological Study of 'Language Attitudes': Constructionism, Context, and the AttitudeBehavior Link. Language and Linguistics Compass 6,4: 212 - 224. Available at:

http://onlinelibrary.wiley.com/doi/10.1002/lnc3.332/abstract (Accessed on 11 April 2017).

https://doi.org/10.1002/lnc3.332

SSA (Statistics South Africa) 2011. Census 2011. Available at: http://www.statssa.gov.za/census2011/default.asp (Accessed on 27 July 2014).

Yperzeele, S. 2009. 'Are You Being Served?' De Rol van Taalattitude bij Publieke Dienstleveringsinteracties in Ruraal Zuid-Afrika. Unpublished Master's dissertation. Ghent: University of Ghent.

Chrismi-Rinda Loth Department of South African Language and Deaf Studies University of the Free State Bloemfontein lothc@ufs.ac.za 